Research Paper

\title{
Prevalence of sexual harassment of nurses and nursing students in China: a meta-analysis of observational studies
}

Liang-Nan Zeng"\#, Qian-Qian Zong2,3\#, Ji-Wen Zhang2\#, Li Lu"\#, Feng-Rong An#, Chee H. Ng5, Gabor S. Ungvari ${ }^{6,7}$, Fang-Yu Yang${ }^{2}$, Teris Cheung, ${ }^{8}$ Ligang Chen ${ }^{1 \bowtie}$, Yu-Tao Xiang ${ }^{\bowtie}$

1. Department of Neurosurgery, The Affiliated Hospital of Southwest Medical University, Sichuan, China

2. School of Nursing, Capital Medical University, Beijing, China

3. The National Clinical Research Center for Mental Disorders \& Beijing Key Laboratory of Mental Disorders, Beijing Anding Hospital, Capital Medical University, Beijing, China

4. Unit of Psychiatry, Faculty of Health Sciences, University of Macau, Macao SAR, China

5. Department of Psychiatry, University of Melbourne, Melbourne, Victoria, Australia

6. The University of Notre Dame Australia / Graylands Hospital, Perth, Australia

7. Division of Psychiatry, School of Medicine, University of Western Australia, Perth, Australia

8. School of Nursing, Hong Kong Polytechnic University, Hong Kong SAR, China

\# These authors contributed equally to the work.

$\square$ Corresponding authors: Dr. Yu-Tao Xiang, 3/F, Building E12, Faculty of Health Sciences, University of Macau, Avenida da Universidade, Taipa, Macau SAR, China. Fax: +853-2288-2314; Phone: +853-8822-4223; E-mail: ytxiang@umac.mo; or Dr. Ligang Chen, the Affiliated Hospital of Southwest Medical University, Sichuan, China; E-mail: afrylm@sina.com

(c) Ivyspring International Publisher. This is an open access article distributed under the terms of the Creative Commons Attribution (CC BY-NC) license (https://creativecommons.org/licenses/by-nc/4.0/). See http://ivyspring.com/terms for full terms and conditions.

Received: 2018.06.27; Accepted: 2018.09.10; Published: 2019.01.29

\begin{abstract}
Sexual harassment experienced by nurses and nursing students is common and significantly associated with negative consequences. This study is a meta-analysis of the pooled prevalence of sexual harassment of nurses and nursing students in China. Electronic databases (PubMed, EMBASE, PsyclNFO, Web of Science and Ovid, China National Knowledge Internet, WanFang, SinoMed and Chinese VIP Information) were independently and systematically searched by two reviewers from their commencement date to 12 March 2018. Forty-one studies that reported the prevalence of sexual harassment were analyzed using the random-effects model. The pooled prevalence of sexual harassment was $7.5 \%(95 \% \mathrm{Cl}$ : $5.5 \%-10.1 \%)$, with $7.5 \%(5.5 \%-10.2 \%)$ in nurses and $7.2 \%$ (3.0\%-16.2\%) in nursing students. Subgroup analyses showed that the year of survey and sample size were significantly associated with the prevalence of sexual harassment, but not the seniority of nursing staff, department, hospital, economic region, timeframe, age, working experience or subtypes of harassment. In China, sexual harassment was found to be common in nurses and nursing students. Considering the significant negative impact of sexual harassment, effective preventive and workplace measures should be developed.
\end{abstract}

Key words: Sexual harassment, nurses, China

\section{Introduction}

Sexual harassment, defined as repeated and unwelcome sexual behavior including its verbal, physical, mental or visual forms [1-3], is common in the workplace. Healthcare workers, especially nursing staff, are more likely to be exposed to offensive behaviors, including sexual harassment, than other professions $[4,5]$. Sexual harassment is associated with negative health consequences, such as physical and mental health problems and impaired occupational performance $[6,7]$.

The results across studies on the pattern of sexual harassment of nursing staff have been conflicting [8], probably due to different sampling methods, measures, and the given sociocultural 
context [4]. For instance, the prevalence of sexual harassment of newly licensed registered nurses in Korea was $22.4 \%$ [9]. Other studies reported that the prevalence of sexual harassment in nurses was $16.2 \%$ in Europe [8], while the corresponding figure was $13.02 \%$ in Ethiopia, $10 \%$ in Gambia $[10,11]$ and $3.9 \%$ in China [12].

In order to develop preventive measures and reduce the negative consequences of sexual harassment of nursing staff, it is necessary to understand the patterns of sexual harassment. However, due to variable sociocultural and economic impact of sexual harassment in different countries, findings in a country cannot be generalized to other countries or regions. Some studies have examined the patterns of sexual harassment of nursing staff in China, which yielded mixed results. For instance, the prevalence of sexual harassment in nurses was $63.4 \%$ in Wuhan [13], and $3.9 \%$ in another survey of 16 provinces of mainland China [12]. In contrast, the corresponding figure was $12.9 \%$ in Taiwan and $4.6 \%$ in Macau [14, 15]. The mixed findings in China gave the impetus to conduct a meta-analysis of the pooled prevalence of sexual harassment of nurses and nursing students in China and examined its associated factors. Both English and Chinese databases were searched for ascertaining studies for this meta-analysis.

\section{Methods}

\section{Search strategy}

This meta-analysis was conducted according to the Preferred Reporting Items for Systematic Reviews and Meta-Analyses (PRISMA) guidelines. Both English (PubMed, EMBASE, PsycINFO, Web of Science and Ovid) and Chinese (China National Knowledge Internet, WanFang, SinoMed and Chinese VIP Information) databases were independently and systematically searched by two reviewers (ZLN and ZQQ) from their commencement date to 12 March 2018. The search terms are shown in Supplemental Table 1 (The asterisk "*" in Supplemental Table 1 is a commonly used wildcard symbol that broadens the search by finding words that start with the same letters). The reference lists of the selected papers were also searched manually to avoid missing any additional papers.

\section{Study selection}

Studies were included if they fulfilled the following criteria: (1) cross-sectional or cohort studies conducted in mainland China, Hong Kong, Macao and Taiwan (only baseline data were extracted in cohort studies); and (2) the prevalence of workplace sexual harassment or its different subtypes, such as physical or verbal sexual harassment, of nurses and/or nursing students were reported.

Three reviewers (ZLN, ZQQ and ZJW) independently screened the literature by reviewing titles and abstracts first, and then reading the full papers. Any discrepancies between the three reviewers in the process were discussed and resolved by involving a fourth reviewer (LL). If more than one paper was published based on the same study, only the paper with the largest sample size was included in the analyses.

\section{Quality evaluation}

The methodological quality of included studies was evaluated by a quality assessment instrument for epidemiological studies [16], which was completed by two independent reviewers (ZQQ and ZJW). The assessment instrument contains the following parts: (1) the targeted population was clearly defined; (2) the sample was recruited by random or consecutive sampling methods; (3) the response rate was equal or more than $70 \%$; (4) the sample was representative; (5) a clear definition of sexual harassment was given; and (6) the instruments used to assess sexual harassment were validated measures. One point was given when a study satisfied each item and a total score was generated by adding the score of each item.

\section{Statistical analysis}

All data were analyzed using the Comprehensive Meta-Analysis statistical software (Version 2.0) (http://www.meta -analysis.com). Heterogeneity across studies was measured using the $I^{2}$ statistics, with $I^{2}$ statistics higher than $50 \%$ being defined as great heterogeneity. Due to diverse demographic characteristics, sampling methods and measures on sexual harassment, prevalence estimates were synthesized using the random-effect model [17]. Subgroup analyses were conducted to investigate the potential sources of heterogeneity based on the following variables: age, working experience and seniority of nursing staff, department, hospital, economic region, geographic regions of greater China (i.e., mainland China vs. Hong Kong/Macao/ Taiwan), year of survey, sample size, timeframe (1 year prevalence vs. others), and subtype of harassment. The seniority of nursing staff consists of nurses and nursing students. According to the National Chinese Bureau of Statistics [18], China is collapsed into four regions for the purpose of this study: east, west, central, and northeast of China. Hospital types included tertiary, secondary, primary hospitals [19]. Year of survey, sample size, mean age and working experience were categorized using the median splitting method. Publication bias was 
assessed by funnel plot and the Egger's regression model [20]. All analyses were two-tailed, and the significance level was set at 0.05 .

\section{Results}

\section{Literature search, study characteristics and quality assessment}

The process of the literature search and selection process are shown in Figure 1. In total, 4,696 records were identified of which 41 studies ( 8 published in English and 33 in Chinese) covering 40,617 participants were included in the meta-analysis. Thirty-seven studies reported the overall prevalence of sexual harassment, two studies [21, 22] provided the prevalence of verbal and physical harassment separately, and another two $[23,24]$ only reported the prevalence of verbal harassment.

Table 1 shows the basic characteristics of the studies included in the meta-analysis. They were published from 2004 to 2018; in the 34 studies with data on gender distribution, $95.81 \%$ of participants were females. Thirty-one studies had nurse participants, 9 had nursing student participants and one study had both nurses and nursing students [25].

The mean score of the quality assessment was 5.1 ranging from 3 to 6 . Five studies [13, 26-29] did not report sampling methods, and 6 studies [14,30-34] did not report the response rate or the response rate was less than $70 \%$. The definition of sexual harassment was not defined in 14 studies [12, 13, 21, 26, 28, 33, 35-42] and the instruments on sexual harassment were not validated in 11 studies [21, 26, 27, 32-36, 43-45].

\section{Prevalence of sexual harassment against nursing staff}

The overall prevalence of sexual harassment from the 37 studies covering 39,486 participants was 7.5\% (95\% CI: 5.5-10.1\%) (Figure 2), 7.5\% (5.5\%-10.2\%) in nurses and $7.2 \%$ in nursing students $(3.0 \%-16.2 \%)$. The pooled 1-year prevalence of sexual harassment was 7.1\% (95\% CI: 5.1\%-9.8\%) (Table 2).

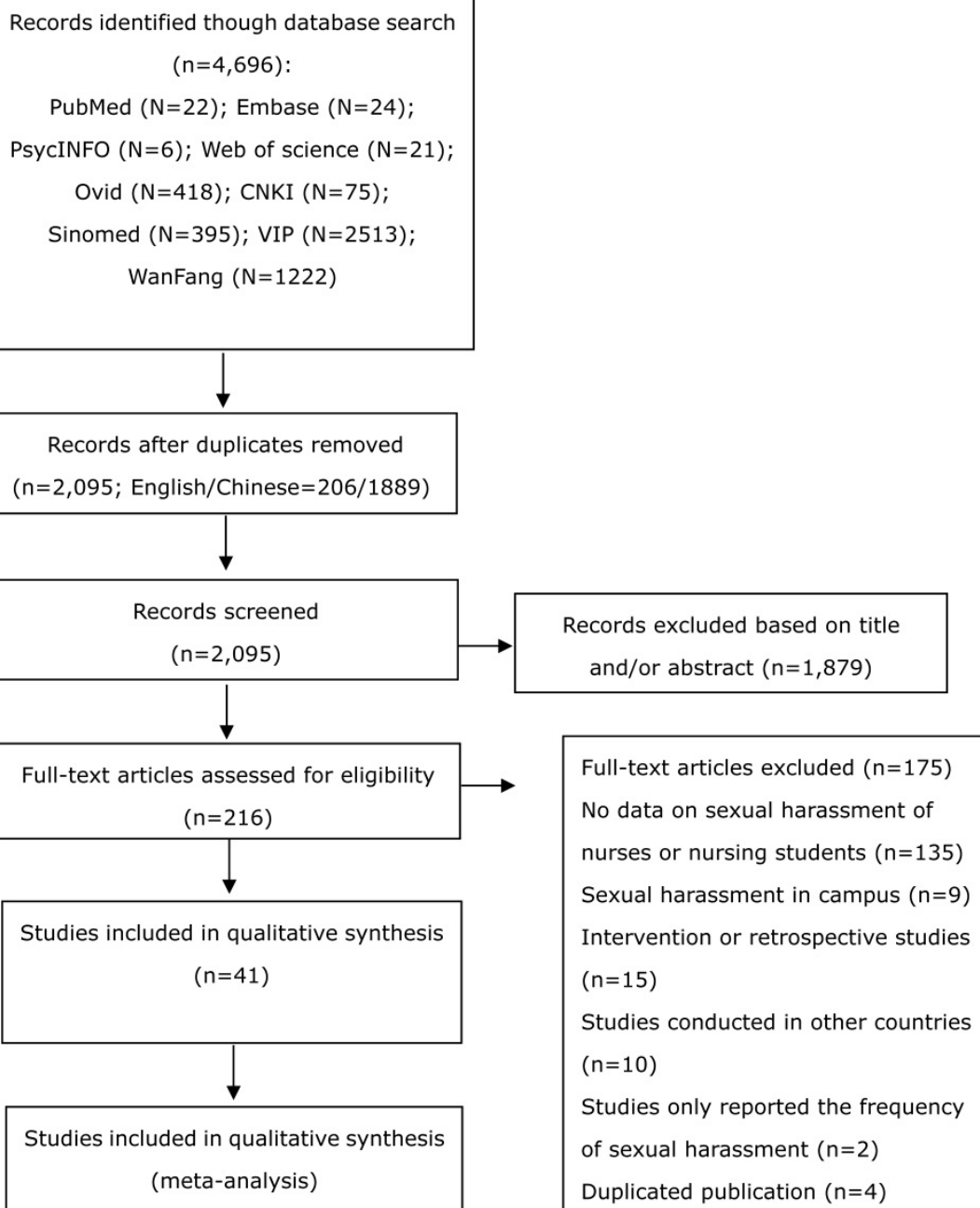

Records after duplicates removed

Records excluded based on title and/or abstract $(n=1,879)$ 
Table 1. Characteristics of the studies included in the meta-analysis

\begin{tabular}{|c|c|c|c|c|c|c|c|c|c|c|c|c|c|c|c|}
\hline No. & $\begin{array}{l}\text { Studies } \\
\text { (First author, } \\
\text { year) }\end{array}$ & $\begin{array}{l}\text { Refer } \\
\text { ences }\end{array}$ & Region & $\begin{array}{l}\text { Economic } \\
\text { region }\end{array}$ & Study year & $\begin{array}{l}\text { Assess } \\
\text { ment } \\
\text { tools }\end{array}$ & $\begin{array}{l}\text { Pop } \\
\text { ulati } \\
\text { on } \\
\text { type }\end{array}$ & $\begin{array}{l}\text { Respons } \\
\text { e } \\
\text { Rate (\%) }\end{array}$ & $\begin{array}{l}\text { Sampl } \\
\text { e } \\
\text { size }\end{array}$ & $\begin{array}{l}\text { Proportio } \\
\mathrm{n} \text { of } \\
\text { females } \\
(\%)\end{array}$ & $\begin{array}{l}\text { Age } \\
(\text { mean } \pm S D \\
)\end{array}$ & $\begin{array}{l}\text { Hospital } \\
\text { type \& }\end{array}$ & Department \# & $\begin{array}{l}\text { Samp } \\
\text { ling } \\
\text { meth } \\
\text { od }\end{array}$ & $\begin{array}{l}\text { Quali } \\
\text { ty } \\
\text { score }\end{array}$ \\
\hline 1 & Chen (2004) & [57] & Guangdong & East & 2003 & SDQ & $\mathrm{N}$ & 100 & 273 & 97 & NR & Mix & Emergency & $\mathrm{C} 1$ & 6 \\
\hline 2 & Xia (2005) & [27] & NR & NR & NR & SDQ & NS & NR & 274 & 100 & 19.97 & NR & NR & NR & 5 \\
\hline 3 & Zhao (2005) & [35] & Gansu & West & 2003 & SDQ & $\mathrm{N}$ & 100 & 21 & 100 & $36.08 \pm 8.86$ & NR & Psychiatry & $\mathrm{C} 1$ & 5 \\
\hline 4 & Kwok (2006) & [31] & Hong Kong & - & 2003-2004 & WVQ & $\mathrm{N}$ & 25 & 420 & 91.89 & NR & NR & Mix & $\mathrm{C} 1$ & 5 \\
\hline 5 & Yang (2008) & [58] & Guangdong & East & 2006-2008 & QDC & $\mathrm{N}$ & 91.35 & 1552 & 95.1 & $29.29 \pm 6.19$ & Mix & Mix & M & 6 \\
\hline 6 & Chen (2009) & [21] & NR & NR & NR & QDWP & NS & 97.25 & 657 & 91.78 & $22.56 \pm 1.07$ & Mix & Mix & $\mathrm{C} 2$ & 5 \\
\hline 7 & Guo (2009) & [22] & Liaoning & Northeast & NR & QDWP & $\mathrm{N}$ & 95.5 & 188 & NR & NR & Tertiary & Emergency & $\mathrm{C} 1$ & 6 \\
\hline 8 & $\mathrm{Xu}(2009)$ & [59] & Shandong & East & 2007 & QDWP & NS & 100 & 536 & NR & $20.41 \pm 2.17$ & NR & Mix & $\mathrm{C} 1, \mathrm{~S}$ & 6 \\
\hline 9 & Gao (2010) & [37] & Sichuan & West & NR & SDQ & $\mathrm{N}$ & 100 & 146 & 93.84 & NR & NR & Psychiatry & $\mathrm{C} 1$ & 5 \\
\hline 10 & Liu (2010) & [38] & NR & NR & 2008-2009 & SDQ & NS & 97.1 & 126 & 100 & NR & Tertiary & Mix & $\mathrm{C} 1$ & 5 \\
\hline 11 & Pai (2011) & [15] & Taiwan & - & NR & WVQ & $\mathrm{N}$ & 77.9 & 521 & 95.59 & $36.2 \pm 7.9$ & NR & NR & $\mathrm{R}$ & 6 \\
\hline 12 & Chen (2011) & [60] & Guangdong & East & 2008 & SDQ & $\mathrm{N}$ & NR & 2339 & NR & NR & Mix & Mix & $\mathrm{C} 1, \mathrm{~S}$ & 6 \\
\hline 13 & Liao (2011) & [44] & $\mathrm{NR}$ & NR & 2009 & SDQ & $\mathrm{N}$ & 100 & 100 & 100 & $34.79 \pm 8.87$ & Mix & Mix & $\mathrm{C} 2$ & 6 \\
\hline 14 & Qiu (2011) & [45] & Guangdong & East & 2010 & SDQ & $\mathrm{N}$ & 100 & 179 & NR & NR & Tertiary & Emergency & $\mathrm{C} 1, \mathrm{~S}$ & 6 \\
\hline 15 & Xiong (2011) & [39] & Hunan & Central & NR & QDD & NS & NR & 436 & 100 & 20.37 & NR & Mix & $\mathrm{C} 1, \mathrm{~S}$ & 5 \\
\hline 16 & Zhu (2011) & [32] & Henan & Central & NR & SDQ & $\mathrm{N}$ & NR & 689 & NR & NR & NR & Mix & $\mathrm{C} 1$ & 5 \\
\hline 17 & Wu (2012) & [33] & NR & NR & 2009 & SDQ & $\mathrm{N}$ & NR & 1033 & 96.7 & NR & Mix & Mix & $\mathrm{R}$ & 4 \\
\hline 18 & Yang (2012) & [34] & Henan & Central & NR & SDQ & $\mathrm{N}$ & NR & 673 & NR & NR & NR & Mix & $\mathrm{C} 1, \mathrm{R}$ & 5 \\
\hline 19 & Zhang (2012) & [24] & Guangdong & East & NR & QDC & $\mathrm{N}$ & 93.75 & 143 & 88.11 & $30.45 \pm 5.74$ & Tertiary & Emergency & $\mathrm{R}$ & 6 \\
\hline 20 & Liu (2013) & [61] & Jilin & Northeast & NR & QDW & $\mathrm{N}$ & 100 & 420 & 100 & $34.65 \pm 9.28$ & Community & NR & $\mathrm{C} 2$ & 6 \\
\hline 21 & Xu (2013) & [28] & Jilin & Northeast & 2012-2013 & SDQ & NS & 100 & 400 & 94.25 & 21.48 & Tertiary & Mix & NR & 4 \\
\hline 22 & Yu (2013) & [23] & Guangdong & East & 2011 & QDC & $\mathrm{N}$ & NR & 143 & 88.11 & $30.45 \pm 5.74$ & Tertiary & Emergency & $\mathrm{C} 2$ & 6 \\
\hline 23 & Fang (2014) & [26] & NR & NR & $2012-2013$ & SDQ & NS & NR & 617 & 91.41 & 21.3 & Mix & Mix & NR & 4 \\
\hline 24 & $\mathrm{Hu}(2014)$ & [62] & Shandong & East & 2013 & QDY & $\mathrm{N}$ & 98.79 & 395 & 79 & $33.72 \pm 7.85$ & Mix & Psychiatry & $\mathrm{C} 1$ & 6 \\
\hline 25 & Lian (2014) & [40] & Fujian & East & 2013 & QDC & $\mathrm{N}$ & NR & 1436 & 90.39 & NR & Mix & Mix & $\mathrm{R}$ & 5 \\
\hline 26 & Zhang (2014) & [29] & Neimenggu & West & NR & QDC & $\mathrm{N}$ & 98.31 & 58 & 91.38 & $26.34 \pm 3.85$ & NR & Emergency & NR & 5 \\
\hline 27 & Guan (2015) & [43] & Beijing & East & $2010-2011$ & SDQ & $\mathrm{N}$ & NR & 444 & 97.07 & 28 & Mix & Emergency & $\mathrm{C} 1$ & 6 \\
\hline 28 & Su (2015) & [63] & Shanxi & Central & 2013-2014 & QDC & $\mathrm{N}$ & NR & 672 & 98.21 & 24.7 & Mix & Mix & $\mathrm{C} 1$ & 6 \\
\hline 29 & Sun (2015) & [25] & Liaoning & Northeast & 2014 & SDQ & Both & 98.9 & 975 & 98.15 & NR & Tertiary & Mix & $\mathrm{R}$ & 6 \\
\hline 30 & Xiao (2015) & [64] & Hunan & Central & 2014 & QDW & $\mathrm{N}$ & NR & 778 & 93.19 & $28.9 \pm 5.26$ & Tertiary & Mix & $\mathrm{R}$ & 6 \\
\hline 31 & Yu (2015) & [65] & Heilongjiang & Northeast & 2014 & QDC & $\mathrm{N}$ & 94.6 & 1597 & 95.87 & $30.03 \pm 6.89$ & Tertiary & Mix & $\mathrm{C} 2$ & 6 \\
\hline 32 & Du (2016) & [66] & Beijing & East & NR & QDWP & NS & NR & 317 & 85.8 & NR & Tertiary & Mix & $\mathrm{C} 2$ & 6 \\
\hline 33 & Fan (2016) & [41] & NR & NR & NR & QDWP & NS & NR & 284 & 95.4 & $24.3 \pm 0.83$ & Mix & Mix & $\mathrm{C} 1$ & 5 \\
\hline 34 & Fang (2016) & [67] & NR & NR & NR & QDC & $\mathrm{N}$ & 93.54 & 608 & 97.86 & $27.43 \pm 3.19$ & Mix & Mix & M & 6 \\
\hline 35 & Cheung (2017) & [14] & Macao & - & 2014 & WVQ & $\mathrm{N}$ & NR & 613 & NR & NR & NR & Mix & $\mathrm{C} 2$ & 5 \\
\hline 36 & $\begin{array}{l}\text { Cheung (2017) } \\
\text { a }\end{array}$ & [30] & Hong Kong & - & 2013 & WVQ & $\mathrm{N}$ & 5.3 & 850 & 87.65 & NR & NR & NR & $\mathrm{C} 1$ & 5 \\
\hline 37 & Shi (2017) & [12] & NR & NR & 2014-2016 & QDC & $\mathrm{N}$ & NR & 15970 & 97.64 & NR & Mix & Mix & M, S & 5 \\
\hline 38 & Zhang (2017) & [42] & NR & NR & 2014 & WVQ & $\mathrm{N}$ & 92.97 & 3004 & 97.04 & $29.37 \pm 6.18$ & Mix & Mix & S & 5 \\
\hline 39 & Niu (2017) & [68] & Beijing & East & 2014 & QDY & $\mathrm{N}$ & 96.6 & 385 & 94.29 & $29.6 \pm 6$ & Mix & Emergency & $\mathrm{C} 2$ & 6 \\
\hline 40 & Yang (2018) & [13] & Hubei & Central & NR & SDQ & $\mathrm{N}$ & NR & 245 & 66.8 & $31.4 \pm 7.43$ & NR & Psychiatry & NR & 4 \\
\hline 41 & Zhou (2018) & [36] & Henan & Central & 2014-2016 & NR & $\mathrm{N}$ & NR & 100 & 97 & 30.14 & Tertiary & Emergency & $\mathrm{C} 1$ & 4 \\
\hline
\end{tabular}

NR: Not reported. SD, standard deviation.

Population type: N: Nurse. NS: Nursing student.

Assessment tools: $\mathrm{SDQ}$, self-designed questionnaire; WVQ, workplace violence in the health sector country case studies research instruments survey questionnaires;

QDC, questionnaire designed by Chen ZH; QDW, questionnaire designed by Wang SY; QDWP, questionnaire designed by Wang PX; QDD, questionnaire designed by Ding DW; QDY, questionnaire designed by Yang XD;

Sampling method: $\mathrm{C} 1$, cluster sampling; $\mathrm{C} 2$, convenient sampling; $\mathrm{M}$, multistage sampling; $\mathrm{R}$, random sampling; S, stratified sampling.

\&: Hospital types include: tertiary, secondary, primary, community and county-level hospitals.

\section{Subgroup analyses}

Subgroup analyses revealed that the prevalence of sexual harassment reported in studies conducted before 2012 was higher than those after 2013 (11.1\% vs. $5.2 \%, P=0.014)$, while the figure was lower in studies with sample size larger than 436 than those with simple size of $=/<436(5.3 \%$ vs $11.1 \%, Q=6.311$, $P=0.012$ ) (Table 2). In contrast, the prevalence of sexual harassment was not significantly associated with mean age, seniority and length of working experience of nursing staff, department, hospital, economic and geographic regions of China, and the timeframe (all $p$ values $>0.05$ ).

Thirteen studies reported at least one type of sexual harassment: 6 studies reported both physical and verbal sexual harassments and 7 studies reported only verbal sexual harassment. The overall prevalence of physical and verbal harassment was $2.2 \%$ and $7.0 \%$, respectively.

\section{Publication bias}

Figure 3 shows the results of the funnel plot and the Egger's test $(t=0.574,95 \%$ CI: $-3.15,5.64 \%, P=0.57)$ showing no publication bias. 


\begin{tabular}{|c|c|c|c|c|c|}
\hline \multirow[t]{2}{*}{ Study name } & \multicolumn{5}{|c|}{ Statistics for each study } \\
\hline & $\begin{array}{l}\text { Event } \\
\text { rate }\end{array}$ & $\begin{array}{l}\text { Lower } \\
\text { limit }\end{array}$ & $\begin{array}{c}\text { Upper } \\
\text { limit }\end{array}$ & Z-Value & p-Value \\
\hline hen $\mathrm{ZH}(2004)$ & 0.088 & 0.060 & 0.128 & -10.945 & 0.000 \\
\hline & & & & & \\
\hline hao WP (2005) & & & & & \\
\hline & & & & & \\
\hline 008) & & & & & \\
\hline & & & & & \\
\hline & & & & & \\
\hline & & & & & \\
\hline & & & & & \\
\hline & & & & & \\
\hline & & & & & \\
\hline & & & & & \\
\hline & & & & & \\
\hline & & & & & \\
\hline & & & & & \\
\hline & & & & & \\
\hline & 0.0 & & & & \\
\hline & 0.28 & & & & \\
\hline & & & & & \\
\hline & & & & & \\
\hline & & & & & \\
\hline & & & & & \\
\hline & & & & & \\
\hline & & & & & 000 \\
\hline & & & & & 00 \\
\hline & & & & & 0.000 \\
\hline & & & & & 0.000 \\
\hline & & & & & 0.000 \\
\hline (1) & 0.028 & & & & 0.000 \\
\hline 10 & 0.072 & & & -16 & 0.000 \\
\hline & & & & -15 & 0.000 \\
\hline Che & 0.01 & & & -13 & 0.000 \\
\hline & 0.039 & 0.0 & & -78 & 0.000 \\
\hline & 0.028 & 0.0 & 0.0 & -31 & 0.000 \\
\hline & 0.039 & 0.024 & 0.06 & -12.1 & 0.000 \\
\hline & 0.608 & 0.546 & 0.667 & & 0.001 \\
\hline Zhou YJ (2018) & & & 0.115 & -6.417 & \\
\hline
\end{tabular}


Funnel Plot of Standard Error by Logit event rate

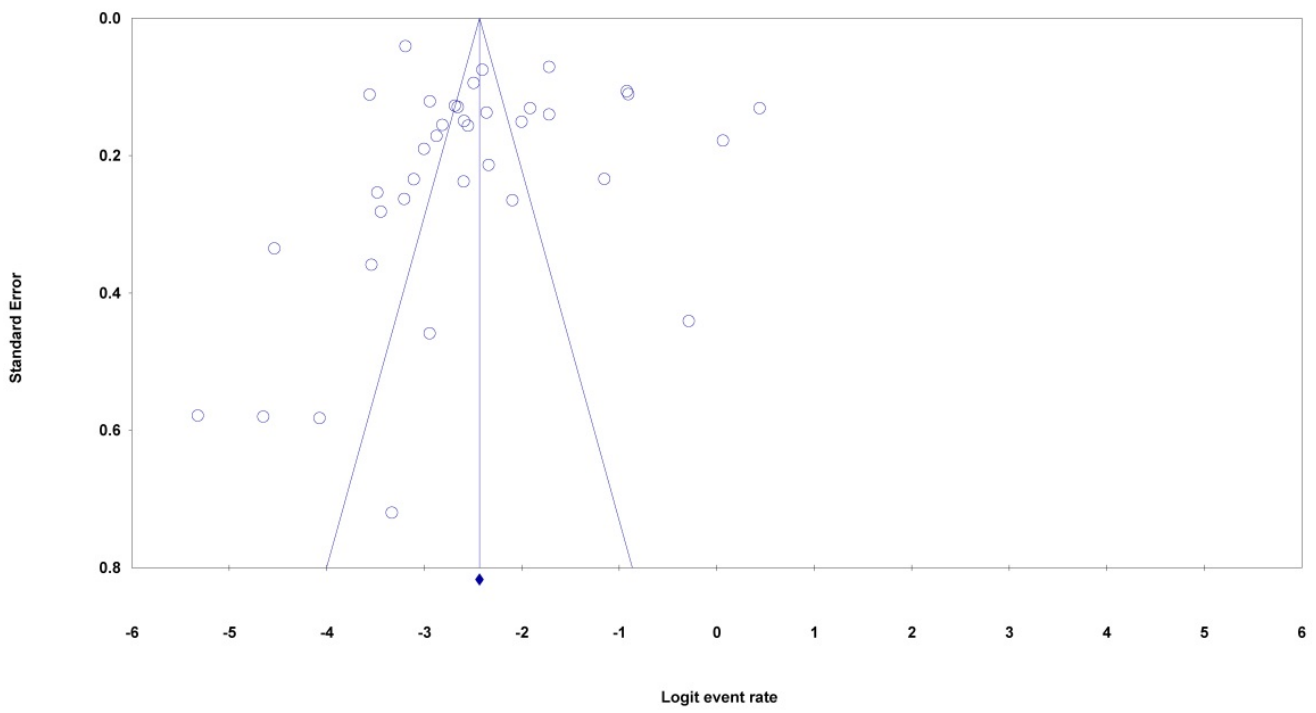

Figure 3. Funnel plot of publication bias for the 37 studies with available data on prevalence of sexual harassment

\section{Discussion}

To the best of our knowledge, this was the first meta-analysis of the prevalence of sexual harassment of nurses and nursing students in China. The overall prevalence of sexual harassment of nursing staff and nursing students was $7.5 \%$ and $7.2 \%$ respectively. This implies that of the estimated 3.79 and 1.8 million registered nurses and nursing students in China in 2017 and 2016, respectively [46, 47], around 284,250 nurses and 129,600 nursing students in China may have been subjected to sexual harassment.

The prevalence of sexual harassment of Chinese nursing staff in this study was lower than the figures reported from most other countries. For example, $13.0 \%$ of nurses reported sexual harassment in the past 6 months in Southern Ethiopia [10], while the corresponding figures were $22.8 \%$ in Malaysia [48] and $22.4 \%$ in South Korea. Different definitions, measures and time frames may partly contribute to the discrepancy between these results. In addition, it is possible that the training and campaign against sexual harassment in medical settings in China have resulted in the lower prevalence of sexual harassment of nursing staff.

In this study the prevalence of sexual harassment was associated with year of survey (2003-2012 vs. 2013-2016, $P=0.014)$. In 2012, the law on the protection of rights of female employees was implemented in China [49], which may have reduced the risk of sexual harassment of female health workers. Similar to other studies [50], smaller simple size was associated with higher prevalence of sexual harassment in this study. There is no explanation for this observation except that the findings of studies with smaller sample size may not have been stable. Maybe participants in a smaller sample could have been more thoroughly interviewed and disclosed more cases of sexual harassment.

A survey in Italy [51] found that the prevalence of sexual harassment of nurses was higher than that of nursing students $(13.9 \%$ vs. $5.8 \% ; P<0.001)$, which was not confirmed in this study $(7.5 \%$ vs. $7.2 \% ; P=0.909)$. In this study, the prevalence of sexual harassment was highest in departments of psychiatry $(28.5 \%)$, which is consistent with previous findings [52]. Compared to patients in other medical departments, psychiatric patients are more likely to present with disinhibited or antisocial or aggressive behaviour including sexual harassment [53]. Older nurses with longer working experience were more likely to experience sexual harassment [54, 55]. This is partly because the experienced nurses are usually responsible for handling more challenging patients, which could increase the likelihood of workplace violence and sexual harassment. However, this finding was not confirmed in the current meta-analysis. Although the difference between verbal and physical harassments did not reach statistically significant level $(7 \%$ vs. $2.2 \%, P=0.216$ ), verbal harassment was more common, which is consistent with a Malaysian study $(46.6 \%$ vs. $20.7 \%)$ [48].

There are several limitations to this meta-analysis. First, most studies did not report the perpetrators of sexual harassment, hence this variable could not be examined. Second, substantial heterogeneity was present in subgroup analyses as it is unavoidable in meta-analysis of epidemiological surveys [56]. Third, most nurses in the included studies were females, therefore the prevalence of 
sexual harassment in male nurses could not be examined. Fourth, there have been no gold standard measures on sexual harassment, therefore the sexual harassment was measured by different instruments across studies. Finally, some relevant factors pertaining to sexual harassment, such as age and sex, were not reported in some studies, which may have affected the findings of subgroup analyses.

In conclusion, sexual harassment, particularly verbal harassment of nurses and nursing students, is common in China. Considering the significant negative impact of sexual harassment, effective preventive and workplace measures should be developed.

\section{Supplementary Material}

Supplementary table.

http://www.ijbs.com/v15p0749s1.pdf

\section{Acknowledgements}

The study was supported by the University of Macau (MYRG2015-00230-FHS; MYRG2016-00005FHS), National Key Research \& Development Program of China (No. 2016YFC1307200), Beijing Municipal Administration of Hospitals Clinical Medicine Development of Special Funding Support (No.ZYLX201607) and Beijing Municipal Administration of Hospitals' Ascent Plan (No. DFL20151801).

\section{Competing Interests}

The authors have declared that no competing interest exists.

\section{References}

1. Bronner G, Peretz C, Ehrenfeld M. Sexual harassment of nurses and nursing students. Journal of advanced nursing. 2003; 42: 637-44

2. Fallahi Khoshknab M, Oskouie F, Ghazanfari N, Najafi F, Tamizi Z, Afshani S, et al. The frequency, contributing and preventive factors of harassment towards health professionals in Iran. International journal of community based nursing and midwifery $2015 \cdot 3$ : 156-64.

3. Nelson R. Sexual harassment in nursing: a long-standing, but rarely studied problem. The American journal of nursing. 2018; 118: 19-20.

4. Nielsen MBD, Kjaer S, Aldrich PT, Madsen IEH, Friborg MK, Rugulies R, et al. Sexual harassment in care work - dilemmas and consequences: A qualitative investigation. International journal of nursing studies. 2017; 70: 122-30.

5. Prasad K. Sexual harassment in the work place. The Nursing journal of India. 2007: 98: 9-10.

6. Abo Ali EA, Saied SM, Elsabagh HM, Zayed HA. Sexual harassment against nursing staff in Tanta university hospitals, Egypt. The Journal of the Egyptian Public Health Association. 2015; 90: 94-100.

7. Lee SK, Song JE, Kim S. Experience and perception of sexual harassment during the clinical practice of Korean nursing students. Asian Nursing Research. 2011; 5: 170-6.

8. Spector PE, Zhou ZE, Che XX. Nurse exposure to physical and nonphysical violence, bullying, and sexual harassment: a quantitative review. International journal of nursing studies. 2014; 51: 72-84.

9. Chang HE, Cho SH. Workplace violence and job outcomes of newly licensed nurses. Asian nursing research. 2016; 10: 271-6.

10. Fute M, Mengesha ZB, Wakgari N, Tessema GA. High prevalence of workplace violence among nurses working at public health facilities in Southern Ethiopia. BMC nursing. 2015; 14: 9.

11. Sisawo EJ, Ouedraogo S, Huang SL. Workplace violence against nurses in the Gambia: mixed methods design. BMC health services research. 2017; 17: 311.
12. Shi L, Zhang DY, Zhou CY, Yang LB, Sun T, Hao TJ, et al. A cross-sectional study on the prevalence and associated risk factors for workplace violence against Chinese nurses. BMJ open. 2017; 7: e013105.

13. Yang BX, Stone TE, Petrini MA, Morris DL. Incidence, type, related factors, and effect of workplace violence on mental health nurses: a cross-sectional survey. Archives of Psychiatric Nursing. 2018; 32: 31-8.

14. Cheung T, Lee PH, Yip PSF. Workplace violence toward physicians and nurses: prevalence and correlates in Macau. International Journal of Environmental Research \& Public Health 2017; 14: 04.

15. Pai HC, Lee $\mathrm{S}$. Risk factors for workplace violence in clinical registered nurses in Taiwan. Journal of Clinical Nursing. 2011; 20: 1405-12.

16. Parker G, Beresford B, Clarke S, Gridley K, Pitman R, Spiers G, et al. Technical report for SCIE research review on the prevalence and incidence of parental mental health problems and the detection, screening and reporting of parental mental health problems [thesis]: University of York; 2008.

17. Higgins JP, Thompson SG, Deeks JJ, Altman DG. Measuring inconsistency in meta-analyses. BMJ (Clinical research ed). 2003; 327: 557-60.

18. The National Bureau of Statistics of China The method to classify China into four economic area: East, West, Central and Northeast (in Chinese). https:// baike.so.com/doc/3057744-3223145 (accessed from Jun. 2018); 2011.

19. Sun T, Gao L, Li F, Shi Y, Xie F, Wang J, et al. Workplace violence, psychological stress, sleep quality and subjective health in Chinese doctors: a large cross-sectional study. BMJ open. 2017; 7: e017182.

20. Egger M, Davey Smith G, Schneider M, Minder C. Bias in meta-analysis detected by a simple, graphical test. BMJ (Clinical research ed). 1997; 315: 629-34.

21. Chen LL. Research on the impact of medical workplace violence on professional attitude of student nurses (in Chinese) [thesis]. Shanxi: Shanxi Medical University; 2009

22. Guo GL. Correlation between job burnout and workplace violence of emergency department's nurses of six top-class hospitals in Shenyang (in Chinese) [thesis]. Liaoning: China Medical University; 2009.

23. Yu T, Hu AL, Wen RJ, Zhang YJ, Lin QP, Wang YS. Analysis on post-traumatic stress disorder and its relative factors of emergency department nurses after suffering from workplace violence (in Chinese). Chinese Journal of Practical Nursing. 2013; 29: 41-4

24. Zhang YJ, Yu T, Hu AL, Wen RJ, Lin QP, Yu N. Current status of workplace violence against emergency department nurses in Guangzhou (in Chinese). Clinical Medical Engineering. 2012; 19: 2045-7.

25. Sun B. An investigation on the nurses hospital violence present situation and the cognition in one hospital of Dalian (in Chinese) [Thesis]. Liaoning: Dalian Medical University; 2015.

26. Fang J, Lu R, Fan HM, He JM. Present investigation about lateral violence which clinical practice nursing students encountered (in Chinese). The Journal of Medical Theory and Practice. 2014; 27: 1845-7.

27. Xia LP. Investigation of sexual harassment among nursing students (in Chinese). Nursing Journal of Chinese People's Liberation Army. 2005; 22: 33-4.

28. $\mathrm{Xu} \mathrm{J}$. The research on the current status of workplace sexual harassment against nursing students in Changchun (in Chinese) [thesis]. Jilin: Jilin University; 2013.

29. Zhang CY. Investigation of the Injury caused by workplace violence of nurses in emergency department (in Chinese). Inner Mongolia Medical Journal. 2014; 46: $1212-4$

30. Cheung T, Yip PS. Workplace violence towards nurses in Hong Kong: prevalence and correlates. BMC public health. 2017; 17: 196

31. Kwok RPW, Law YK, Li KE, Ng YC, Cheung MH, Fung VKP, et al. Prevalence of workplace violence against nurses in Hong Kong. Hong Kong Medical Journal. 2006; 12: 6-9.

32. Zhu W, Yang LF, Lou XP, Zhao XY, Wang K. The survey on the workplacel violence in medical workplaces of general hospitals in Zhengzhou (in Chinese). Chinese Health Service Management. 2011; 28: 334-6.

33. Wu SY, Zhu W, Li HY, Lin SW, Chai WL, Wang XR. Workplace violence and influencing factors among medical professionals in China. American Journal of Industrial Medicine. 2012; 55: 1000-8.

34. Yang LP. The relationship between medical workplace violence and job bumout as well as sub-health in medical staffs in a city (in Chinese) [thesis]. Henan: Zhengzhou University; 2012.

35. Zhao WP, Luo LJ, Sun JX. Survey on sexual harassment against female nurses in psychiatry department (in Chinese). Journal of Clinical Psychosomatic Diseases. 2005; 11: 148-9.

36. Zhou YJ. Investigation on attack events of nurses in emergency department and its influence on psychological stress (in Chinese). Chinese Journal of Health Psychology. 2018; 26: 392-5.

37. Gao YE. Occupational hazard factors and protective measures for nurses in psychiatry department (in Chinese). Medical Journal of Chinese People's Health. 2010; 22: 506-7.

38. Liu MQ, Zhuang JY, Rao SQ, Huang XM. Investigation on the sexual harassment of female nursing students at workplace (in Chinese). Chinese Journal of Modern Nursing. 2010; 16: 281-3.

39. Xiong $\mathrm{XL}$. The survey of internship nurse abuse in Hunan province and its relationship with anxiety and depression (in Chinese) [thesis]. Hunan: Central South University; 2011.

40. Lian JJ. Investigation of the prevalence of workplace violence among nurses in general hospitals in Fuzhou area (in Chinese). Fujian Medical Journal. 2014; 36: $132-4$ 
41. Fan YY, Cui BH, Shang QM, Lv QY. Research on the workplace violence and its effect on the professional commitment of nursing students (in Chinese). China Higher Medical Education 2016: 33-4+124.

42. Zhang LY, Wang AN, Xie X, Zhou YH, Li J, Yang LJ, et al. Workplace violence against nurses: a cross-sectional study. International Journal of Nursing Studies. 2017; 72: 8-14.

43. Guan RY, Ge BL, Gu BH, Sun HY. Relationship of tension to structural violence and social acknowledgement in emergency nurses (in Chinese). Chinese Mental Health Journal. 2015; 29: 452-6.

44. Liao MR, Ao F, Wang AQ. Investigation on patient-commited sexual harassment on female nurses (in Chinese). Journal of Nursing Science. 2011; 26: 57-8.

45. Qiu YR, Wang JW, Wu HW. The effect of workplace violence on mental health of nurses in emergency department (in Chinese). Chinese Journal of Modern Nursing. 2011; 17: 2995-7.

46. National Bureau of Statistic of the People's Republic of China Statistical communique of the People's Republic of China on national economic and social development in 2017 (in Chinese). http://www.stats.gov.cn/tjsj/zxfb/201802/t20180228_1585631.html (accessed from June 15. 2018); 2017.

47. Ministry of Education of People's Republic of China. Initially establish the standardized medical education system with Chinese characteristics, and major breakthroughs in medical education reform in China (in Chinese). http://www.moe.gov.cn/jyb_xwfb/s5147/201707/t20170711_309097.html (accessed from June 15. 2018); 2017.

48. Suhaila O, Rampal KG. Prevalence of sexual harassment and its associated factors among registered nurses working in government hospitals in Melaka State, Malaysia. The Medical journal of Malaysia. 2012; 67: 506-17.

49. The Central People's Government of the People's Republic of China. Special regulations for the protection of female employees (in Chinese) http://www.gov.cn/flfg/2012-05/07/content_2131582.htm (accessed from June 15. 2018); 2012.

50. Cao XL, Wang SB, Zhong BL, Zhang L, Ungvari GS, $\mathrm{Ng} \mathrm{CH}$, et al. The prevalence of insomnia in the general population in China: A meta-analysis. PloS one. 2017; 12: e0170772.

51. Magnavita N, Heponiemi T. Workplace violence against nursing students and nurses: an Italian experience. Journal of nursing scholarship. 2011; 43: 203-10.

52. Nijman H, Bowers L, Oud N, Jansen G. Psychiatric nurses' experiences with inpatient aggression. Aggressive Behavior. 2005; 31: 217-27.

53. Inoue M, Tsukano K, Muraoka M, Kaneko F, Okamura H. Psychological impact of verbal abuse and violence by patients on nurses working in psychiatric departments. Psychiatry and clinical neurosciences. 2006; 60: 29-36.

54. Celik Y, Celik SS. Sexual harassment against nurses in Turkey. Journal of nursing scholarship : an official publication of Sigma Theta Tau International Honor Society of Nursing. 2007; 39: 200-6.

55. Valente SM, Bullough V. Sexual harassment of nurses in the workplace. Journal of nursing care quality. 2004; 19: 234-41.

56. Li L, Wang YY, Wang SB, Zhang L, Li L, Xu DD, et al. Prevalence of sleep disturbances in Chinese university students: a comprehensive meta-analysis. Journal of sleep research. 2018; 27: e12648

57. Chen ZH, Wang SY. Investigation of psychological workplace violence against nurses in emergency department (in Chinese). Journal of Nursing Science. 2004; 19: 3-6.

58. Yang XD. A descriptive study of workplace violence against nurses in general hospitals in Shenzhen city (in Chinese) [thesis]. Beijing: Peking Union Medical College; 2008.

59. Xu ZQ. The influence of workplace violence on the work attitude of nursing students (in Chinese). China Medical Herald. 2009; 6: 116-8.

60. Chen ZH. An epidemiological study of hospital workplace violence in Guangzhou city (in Chinese) [thesis]. Guangdong: Southern Medical University; 2011.

61. Liu LT. A study of the current status and correlative factors of workplace violence against community nurses (in Chinese) [thesis]. Jilin: Jilin University; 2013.

62. Hu CF. Study on the relationship among workplace violence organizational commitment and turnover intention in psychiatric nurses (in Chinese) [thesis]. Shandong: Shan Dong University; 2014.

63. Su TZ, Ding MC. The current situation and prevention strategies of Taiyuan general hospitals' nurses suffer from the medical violence (in Chinese). China Health Law. 2015; 23: 89-94.

64. Xiao J, Xiong Y, Sha DR, Qiu XR. Investigation on the status of workplace violence of nurses in Changsha city (in Chinese). Medical Information 2015; 28: 111.

65. Yu Y, Sui SJ. The prevalence and predictors of workplace violence against nurses in Harbin (in Chinese). Journal of Nursing Science. 2015; 30: 1-5.

66. Du SS, Wang YP, Xin YY. The influence and its countermeasures of workplace violence on the professional attitude of nursing students (in Chinese). Medical Information 2016; 29: 322-3.

67. Fang LM, Ding MC, Wang PQ. Research on workplace violence from the perspective of social conflict theory (in Chinese). Hospital Management Forum. 2016; 33: 20-4.

68. Niu YT, Xiao GQ, Lu O, Li XE. A survey of workplace violence and its related cognition and demands of nurses in emergency department (in Chinese) Journal of Modern Nursing. 2017; 23: 1117-21. 